\title{
Comparative viral metagenomics from chicken feces and farm dust in the Netherlands
}

Kirsty T. T. Kwok ${ }^{a} \#$, Myrna M. T. de Rooij ${ }^{b}$, Aniek B. Messink ${ }^{b}$, Inge M. Wouters ${ }^{b}$, Lidwien A. M. Smit ${ }^{b}$,

Dick J.J. Heederik ${ }^{b}$, Marion P. G. Koopmans ${ }^{a}$, My V. T. Phan ${ }^{a}$

${ }^{a}$ Department of Viroscience, Erasmus Medical Center, Rotterdam, The Netherlands

${ }^{\mathrm{b}}$ Institute for Risk Assessment Sciences (IRAS), Utrecht University, Utrecht, The Netherlands

Running Head: Virome of Dutch farmed chicken feces and farm dust

\# Address correspondence to Kirsty T. T. Kwok, tt.kwok@erasmusmc.nl.

Keywords: fecal virome; virome; dust; airborne farm dust; viral metagenomics; picornavirus; astrovirus; calicivirus; poultry

Word counts for main text: 4019 words ( $\max =5000$ words) 


\section{ABSTRACT (250 words, word limit $=\mathbf{2 5 0}$ words)}

2 Livestock animals housed in close proximity to humans can act as sources or intermediate hosts

facilitating animal-to-human transmission of zoonotic diseases. Understanding virus diversity in livestock is important for identifying potential zoonotic threats and for ensuring animal health and safe livestock production. Here, we report viral metagenomic characterization of chicken feces $(\mathrm{N}=51)$ and paired farm dust samples $(\mathrm{N}=13)$ using metagenomic deep sequencing. Samples were collected at 4-5 time points in three broiler farms in the Netherlands. Viruses in the Parvoviridae and Picornaviridae families were the most prevalent, detected in all feces and dust samples and in all feces and $85 \%$ of dust samples, respectively. Virus composition found in chicken feces and corresponding dust samples were similar.

Great genomic diversity was identified in Picornaviridae and 46 sequences from five picornavirus genera (Sicinivirus, Megrivirus, Anatvirus, Gallivirus and Avisvirus) were detected. For calicivirus, Basovirus and an unclassified novel chicken calicivirus were identified in 13 fecal and 1 dust samples. Two distinct types of chicken astroviruses were identified. Phylogenetic analyses of identified virus sequences from Picornaviridae, Astroviridae and Caliciviridae suggested that viral sequences obtained from different farms are often more closely related to each other than global reference sequences, and sequences from feces and paired dust samples also clustered together. Importantly, our sequencing methodology enabled the recover viral genome sequences from farm dusts, allowing the tracking of virus chatter between livestock animals and their farm environment. This study, albeit relative sample size, does expand current knowledge of virus communities in chickens and surrounding dusts.

\section{IMPORTANCE (147 words, word limit = 150 words)}

Chickens may harbor various zoonotic pathogens, some of which can cause severe clinical outcomes in animals and humans. Farm dust can act as vector to facilitate zoonoses transmission. Here, we report the metagenomic characterization of virus communities of chicken feces and paired farm dust samples collected at multiple time points during the production cycle in broiler farms in the Netherlands. Parvoviridae and Picornaviridae were most frequently detected. We also identified novel astrovirus and calicivirus sequences that would inform future virus taxonomy classification. This is the first study to characterize virus communities in farmed chickens and paired farm dust samples. We also describe a 
could help setting up a surveillance baseline for tracking virus flow between chickens and their farm environment which could guide zoonotic outbreak preparedness and health risk assessment of farm exposure.

\section{INTRODUCTION}

Most emerging infectious diseases are of zoonotic origins (1). While $71.8 \%$ of zoonoses originated from wildlife, the emergence of MERS-CoV (2) and Nipah virus (3) has shown that livestock can act as intermediate hosts and/or reservoirs which can sustain zoonotic transmission at the wildlife-livestockhuman interface. In addition to passing viruses from wildlife to humans, livestock is also reservoir of zoonotic pathogens, such as bacteria Coxiella burnetii (C. burnettii) that causes Q-fever in goats, sheep and cattle (4), and avian influenza $(5,6)$. Additionally, epidemiological studies have found evidence for increased risk of respiratory disease in persons with exposure to large scale animal farming $(7,8)$. In part, this can be attributed to farm dust exposure for which adverse health effects have been demonstrated (9-11), and the potential of zoonotic infections in these cases could be important yet under-reported. For instance, a Q-fever outbreak affecting approximately 4,000 people was reported in the Netherlands in 2007-2010 that was linked to circulation of C. burnettii in local dairy goat farms and dairy sheep farms (12). Q-fever was not notifiable in small ruminant farms in the Netherlands before the outbreak, making early detection of zoonotic transmission of $C$. burnettii challenging (13). Similarly, MERS-CoV had been circulating among dromedary camels long before it was recognized as a cause of severe respiratory disease in humans (14). These livestock-associated zoonotic disease outbreaks emphasize that continued surveillance of health risks due to livestock exposure is essential, especially when the intensification of livestock production is widely practiced to keep up the increasing food demand for the growing population (15).

Advances in Next-Generation Sequencing (NGS) technology have allowed simultaneous and unbiased detection of all viruses and microbes in a single sample, offering great potential in catch-all infectious disease surveillance. This metagenomic NGS (mNGS) approach combines the detection of known target pathogens with identification of novel and/or rare viruses $(16,17)$ and characterization of complex viral communities $(18,19)$. Indeed, numerous reports of virus diversity of animals including bats (20-22), pigs (23-25), wild birds $(26,27)$, and chickens (28) have been published since the invention 
of NGS. Our previously published systematic review of all available viral mNGS studies of common livestock (29) found that metadata of available mNGS studies is often patchy and majority of the studies only had a very small sample size $(\mathrm{N} \leq 10)$. Sequencing data of most studies was also not publicly available. Continued surveillance of virus communities in common livestock following the "FAIR" data principle (Findable, Accessible, Interoperable and Reusable) (30) could provide a better understanding of what is normal virus diversity in livestock that is an essential baseline for early detection of potential zoonotic and/or animal pathogens using mNGS.

Chickens (Gallus gallus domesticus) are the most abundant domestic livestock. According to the Food and Agriculture Organization of the United Nations (FAO), the global chicken population was $>22$ billion birds in 2017 (31). Chicken products include meats and eggs that are produced by broiler and layer chickens respectively, and spent layer chickens can be harvested for meats as well. Chicken farming ranges from backyard to large-scale commercial farms that house ten-thousands of chickens. The broiler production systems usually follow a pyramidal selective breeding structure, with four generations (top to bottom: great grandparents [GGPs], grandparents [GPs], parent breeders and broilers) (32). Briefly, GGPs are produced by a few breeder farms and their offspring are the GPs that produce parent breeders. Broilers are the final offspring that are grown for consumption. The Netherlands is the second largest agricultural exporter in the world $(33,34)$. There are $>1$ billion housed chickens and 1,741 chicken farms in the Netherlands in 2020, in which one-third of them $(\mathrm{N}=637)$ are broiler farms (35).

Chicken can carry various pathogens such as Salmonella (36), Campylobacter (37) and avian influenza viruses including subtypes that can cause severe infection in humans like H5N1 (38) and H7N9 (5); and it has been found that avian influenza virus can be transmitted to humans as a result of close exposure to contaminated chicken (6). Monitoring virus diversity in chickens is a key component to setting the baseline for identifying potential zoonotic threats. Meanwhile, little is known about the virome composition of chicken farm dust although it has been suggested that farm dust might play a role in infectious disease transmission $(39,40)$. Farm dust consists of animal feed, bedding material, animal feces, dander, mites and microorganisms (43), as well as poultry feathers in the case of poultry farm dust; and farm dust exposure may cause adverse health effects $(41,42)$. Most studies on farm dust 
have focused on measuring antimicrobial genes $(44)$ and endotoxins $(9,11)$, yet limited has been done to document the viral content of farm dust samples.

Here, we document metagenomic characterization of virus diversity in a comprehensive sample set of chicken feces and paired farm dust samples longitudinally collected at multiple time points in three commercial broiler farms across the Netherlands. We show that chicken fecal virome and farm dust virome are highly comparable and stable over time, host age and farms. This study provides useful insights in understanding the virus flows between chickens and poultry farm environments and would contribute to the continued effort of One Health surveillance.

\section{RESULTS}

\subsection{Comparative virus prevalence in chicken feces and farm dust}

A total of 56 pooled chicken feces and 46 individual farm dust samples were collected. Five chicken fecal samples were excluded due to insufficient cDNA concentration for library preparation. Individual farm dust samples collected at the same sampling moment from the same farm were pooled together during sample processing for sequencing, making up a final set of 13 pooled farm dust samples. Metagenomic deep sequencing of pooled chicken feces $(\mathrm{N}=51)$ and pooled chicken farm dust samples $(\mathrm{N}=13)$ generated ca 1-2 million and 1-3 million reads per sample, respectively.

From the total of 64 chicken feces and farm dust samples analyzed, Parvoviridae was consistently detected in all samples, followed by Picornaviridae with a $100 \%$ and $85 \%$ prevalence in chicken feces and dust samples respectively (Table 1). Astroviridae was the third most prevalent family detected in $82 \%$ chicken feces and $85 \%$ of farm dust samples, followed by Caliciviridae with $78 \%$ (chicken feces) and 69\% (farm dust samples) prevalence. The pattern of virus detection observed in dust samples was similar to that in chicken feces, suggesting that dust could play a role in the virus transmission of these animal viruses (Table 1 and Figure S1).

Although the detection frequency of Parvoviridae was slightly higher than Picornaviridae, the number of Picornaviridae contigs detected was the highest (Figure 1). Within the Picornaviridae family, Sicinivirus was consistently detected in all chicken feces and 69\% of farm dust samples (Table 2), followed by Anativirus (chicken feces: 70\%; farm dust samples: 61\%), and Megrivirus (chicken feces: 43\%; farm dust samples: 46\%). Of note, the number of contigs detected in different picornavirus genera 
116 corresponded to the prevalence pattern (Figure 2 \& Figure S2). In particular, Anatvirus, Gallivirus,

117 Megrivirus and Sicinivirus were detected in all three farms, while Orivirus was only identified in farm

118 F_01 and F_03 and Avisivirus was only found in farm F_03 (Figure S2). When looking at virus family level, 119 we did not observe any substantial differences in overall viral contents (Figure 1) and virus-specific 120 prevalence (Figure S1) of samples from different farms and from different production cycles (age) within 121 farms.

122

\subsection{Genomic diversity in viruses identified from chicken feces and farm dust}

\subsubsection{Picornaviridae}

Phylogenetic construction was performed to compare the reported Picornaviridae sequences

126 from 5 genera (Avisvirus, Anatvirus, Gallivirus, Megrivirus and Sicinivirus) with global sequences. Forty-

127 six picornavirus sequences with $\geq 80 \%$ genome coverage (chicken feces: 38 ; farm dust samples: 8 ) were

128 included in the phylogenetic analysis of the polyprotein region. The maximum-likelihood (ML)

129 phylogenetic tree (Figure 3) showed that the sequences identified from farm F_03, albeit small number

130 ( $\mathrm{N}=12)$, belonged to all 5 different genera Avisvirus, Anatvirus, Gallivirus, Megrivirus and Sicinivirus,

131 suggesting a high viral diversity circulating among chicken in this farm. Interestingly, farm F_02 with the

132 highest number of picornavirus contigs identified $(\mathrm{N}=31)$ has a moderate level of viral diversity, with

133 these contigs belonging to 3 genera Anativirus, Sicinivirus and Megrivirus. Only 3 picornavirus genomic

134 sequences identified were from farm F_01, belonging to Sicinivirus ( $N=1)$ and Anativirus $(\mathrm{N}=2)$.

135 Sicinivirus and Anativirus are the most prevalent virus genera found with virus sequences detected in all

1363 farms, while sequences of Gallivirus and Avisivirus were less prevalent, found in only 1 farm, farm

137 F_03.

Genome sequences detected from farm dust samples belonged to Sicinivirus and Megrivirus

139 from farm F_02 that clustered with sequences identified in chicken feces from the same farm (Figure 3).

140 Viruses in the Sicinivirus genus were detected in all chicken feces samples and 69\% of dust samples with

141 the highest number of viral contigs identified in each sample as compared to other genera in the

142 Picornaviridae family. Slightly longer branches in the Sicinivirus sequences in the ML tree indicates

143 higher diversity within this Sicinivirus clade (Figure 3). We further reconstructed a ML tree for all 144 identified Sicinivirus polyprotein nucleotide sequences ( $N=15$; chicken feces: 11; farm dust samples: 4) in 
145 this study and compared them with global reference sequences (Figure 4). Two sequences from chicken 146 feces (V_M_005_picorna_5 from farm F_01 and V_M_034_picorna_3 from farm F_03) were most

147 distinct from the rest of the identified sequences (sharing only 69.4-72.3\% nt identity) and were most

148 closely related to strain JSY previously identified in China (78.9-79.0\% nt identity). Other Sicinivirus

149 sequences from the same farm often formed a monophyletic lineage, suggesting within-farm Sicinivirus

150 sequences are highly genetically similar. Viruses identified from chicken feces and farm dust samples

151 consistently clustered with each other forming their own sub-clusters within major clades in the ML

152 trees, indicating high similarity between sequences from feces and dusts and that they are more closely

153 related as compared to global reference sequences.

154

155

\subsubsection{Astroviridae}

Sixteen astrovirus sequences with $\geq 80 \%$ genome coverage were identified from this study, among which only 1 astrovirus sequence was found in farm dust (VE_7_astro_14; farm F_02). There was only 1 astrovirus genomic sequence from farm F_01. RNA-dependent RNA polymerase (RdRp) and capsid regions of these sequences were extracted for phylogenetic analyses (Figure 5A and 5B, respectively). ML trees of both regions showed that these 16 sequences belonged to two distinct lineages, $A 1$ and $A 2$ (Figure 5). Sequences from farm F_02 and F_03 were found in both lineages A1 and $A 2$, suggesting co-circulation of different astrovirus strains in both farms. The 12 sequences from lineage A1 were most closely related to avian nephritis virus strains previously reported in China and Brazil, while the 4 sequences from lineage A2 were more closely related to each other and clustered with chicken astroviruses previously identified in Malaysia, Canada and the USA. The 12 sequences from lineage A1 shared $96-100 \%$ amino acid (aa) identity in the RdRp region while 4 sequences from lineage A2 shared a higher $99-100 \%$ aa identity. For the less conserved capsid region, three small sub-lineages can be observed within lineage A1 (Figure 5B). Amino acid identity matrix also supported this observation that intra-sub-lineage identity (range $87 \%-100 \%$ ) is higher than inter-sub-lineage identity (range 64-74\%). Notably, the only astrovirus sequence found in dust (strain VE_7_astro_14) was identical to astrovirus recovered from its paired chicken feces sample (strain V_M_038_astro_4) at the same farm. 


\subsubsection{Caliciviridae}

Similar to astrovirus distribution in feces versus dusts, 13 out of 14 calicivirus sequences ( $\geq 80 \%$ genome coverage) identified were recovered from fecal samples and only 1 calicivirus sequence identified from dust sample. Partial ORF1 polyprotein region of these sequences was extracted to construct ML tree comparing the local calicivirus with global sequences. The ML tree showed that the reported calicivirus sequences formed two distinct lineages (C1 and C2) (Figure 6). All calicivirus sequences from farm F_02 and F_03 belonged to lineage $\mathrm{C} 1$, while sequences from $\mathrm{F} \_01$ belonged to both lineages C1 and C2 suggesting higher diversity of calicivirus circulating in farm F_01. The 11 sequences in lineage $\mathrm{C} 1$ shared $98.7-100 \%$ aa identity despite being collected from different farms and they shared 97.2-99.1\% aa similarity with two partial ORF1 sequences identified in Germany in 2010 (F10026n and F10034n). BLAST searches and multiple sequence alignment indicated that these 11 local calicivirus sequences are the first report of complete ORF1 sequence of that particular chicken calicivirus lineage. The only calicivirus sequence from dust (VE_8_calici_66) clustered in lineage C1. The 3 sequences in lineage C2 are highly similar, sharing 99.9-100\% aa identity and were all collected from farm F_01 at two time points. These 3 sequences shared 93.8-96.8\% aa similarity with reference sequences from USA, Korea, Brazil and Germany (Bavaria virus, Bavovirus genus).

\subsubsection{Coronaviridae}

Three nearly-complete coronavirus genome sequences were identified in 3 chicken feces (V_M_001, V_M_002 and V_M_003) from farm F_01. BLAST analyses showed that these sequences are Infectious bronchitis virus (IBV) strains and share 99.92-99.95\% identity at the nucleotide level with IBV vaccine strain 4/91 (GenBank accession number KF377577), suggesting these IBV may possibly be viral shedding following vaccination or environmental contamination as vaccines were given by drinking water.

\section{DISCUSSION}

Livestock kept in close proximity to humans can act as intermediate hosts and/or sources to amplify zoonotic disease transmission (45). The surge of zoonotic disease outbreaks around the world has prompted the need for more proactive surveillance strategy involving animal surveillance, which could potentially guide zoonotic outbreak preparedness. Chicken is the most abundant livestock in the world 
(31) and has been identified as reservoir for various zoonotic pathogens $(37,38)$. In this study, we

employed viral metagenomic deep sequencing to document total viruses present in chicken feces and paired farm dust, data from which provide insights into virus flow between chickens and their farm environment as well as a platform for future surveillance in farm animals and environmental samples. To our knowledge, this is the first study characterizing the virome (viral metagenomics) of chicken feces and farm dust from the Netherlands.

In this study, we described a primer-independent viral metagenomic deep sequencing strategy to sequence viruses in dust samples that usually possess low viral load and are hence difficult to sequence. We further demonstrated that using this method, we were able to recover long viral sequences with $\geq 80 \%$ genome coverage from farm dust samples. This method could be adapted for future metagenomic characterization of virus diversity in dust samples. Farm dust is associated with adverse respiratory effects observed in farm workers with prolonged exposure (41). There is a knowledge gap in virus diversity of farm dust. Characterizing farm dust virome could aid in investigating possible health effects of occupational and environmental exposure to virus-containing farm dust.

Phylogenetic analyses indicated that viruses identified from farm dust samples were genetically closely related to viruses identified from chicken feces collected from the same farm, suggesting that viruses identified in dust were attributed to the viruses circulating in the chicken feces that is also source of farm dust. This observation is in agreement with a previous study that reported the correlation found in the resistomes between animal feces and farm dust (46). More importantly, the detection of chicken-related virus sequences in dust samples raises the possibility of dust-borne transmission of viruses especially important in the cases of chicken and/or zoonotic pathogenic viruses (47), although infectivity of the viruses identified was not confirmed as no virus culture was performed in our study. Future investigation on the infectivity of viruses in farm dust could provide useful insights in mapping virus flows between and among chickens as well as chicken and surround environment including dust, which collectively would guide future outbreak control strategies in farms.

Viruses identified in chicken feces from different farms are phylogenetically closely related to each other and formed sub-lineages or monophyletic lineages when comparing to global related sequences. This could possibly be explained by the pyramid structure of broiler production system which chicks were bought from a few suppliers that were not bred by the broiler farmers; in other words, chicks 
carrying similar viruses from a supplier were then distributed to different broiler farmers, and further spread within the farms, leading to similar viruses circulating in different broiler farms. Of note, the pyramid production structure was also suggested as a possible transmission routes for ESBL/pAmpC producing bacteria between broiler farms (32). Future characterization of virus diversity of chickens from the top part of the pyramid is needed to confirm the speculation.

Viruses belonging to five genera of the Picornaviridae family were identified in our study, suggesting a great diversity of picornaviruses circulating in chickens, which is consistent with previous studies that detected various picornavirus genera in chicken respiratory samples $(48,49)$. Astroviruses identified in this study clustered in two distinct phylogenetic lineages; these astroviruses could present possible new genotypes. For astrovirus, all chicken astroviruses are grouped to one single species according to the current taxonomy assignment from International Committee on Taxonomy of Viruses (50). Current classification of avastrovirus is based on phylogenetic analysis of capsid (ORF2) amino acid sequences (51). More comprehensive assignment of genotypes is hindered by limited number of complete capsid sequences. A similar observation was seen in Caliciviridae, we identified two types of caliciviruses forming two distinct lineages in the ML tree. Lineage C2 is closely related to the Bavovirus genus, while the sequences from C1 are most related to an unclassified chicken calicivirus strain F10026n (52) that only possessed a partial ORF1 sequence. Our data have provided 16 astrovirus and 14 calicivirus sequences, which help expand the current knowledge of chicken astrovirus and calicivirus diversity and could potentially contribute to improve future taxonomy assignment.

We observed that viruses in the Parvoviridae and Picornaviridae families were consistently detected in chicken feces and farm dust samples at multiple time points in all three farms. These virus families could potentially present the "signature" viruses to indicate chicken exposure. By combining these viruses together, a chicken viral fingerprint profile may be built that can be used to map the virus flow between farms and surrounding areas. In case of any future avian-associated zoonotic outbreaks, these marker viruses could also be used to assess spatial transmission risk in poultry farm surrounding areas $(29,53)$. Additionally, these viruses could also be used as markers to assess the efficiency of disinfection procedures in farms and surrounding environments although stabilities of different viruses may differ due to different structures. Since this is the first study of its kind in chicken and farm dust in the Netherlands, further and perhaps larger scale of surveillance with the inclusion of samples from layer 
261 hens and more environmental samples from surrounding areas are certainly necessary to confirm our

observation and the applicability of using these identified viruses as signature virus fingerprint.

In conclusion, we provide a comprehensive dataset of virus diversity of chicken feces and paired farm dust samples. Highly prevalent viruses like parvoviruses and picornaviruses were detected and they could potentially serve as marker viruses to follow the virus flows between chickens and their surrounding environment. Identification of novel calicivirus and astrovirus sequences indicates that continued effort is needed for increasing understanding of virus diversity in chicken feces. Viral surveillance using the One Health approach is warranted for early detection of zoonotic viruses. In the long term, understanding virus flows at the animal-human-environmental interface is vital for identifying potential zoonotic threats and zoonotic outbreak control and preparedness.

\section{MATERIALS AND METHODS}

\subsection{Sample collection}

Pooled chicken feces and farm dust samples were collected in three commercial broiler farms in the Netherlands at 4-5 time points from May to August 2019. The three commercial broiler farms are located in three different regions in the Netherlands (Western part: Noord/Zuid-Holland region; Northern part: Friesland/Groningen region; Eastern part: Gelderland region). Detailed sampling strategy and sample metadata is described in Table 3. Each pooled poultry fecal sample contains fresh fecal material from 3-4 chicks. Farm dust samples were collected using a passive air sampling approach using electrostatic dustfall collectors (EDCs) $(54,55)$. Electrostatic cloths were sterilized through overnight incubation at $200^{\circ} \mathrm{C}$. Sterilized electrostatic cloths were then fixed to a pre-cleaned plastic frame. EDCs were exposed for 7 days at 1 meter above the floor with the electrostatic cloths facing up in broiler farms to enable sampling of settling airborne dust instead of resuspended dust from the floor. EDCs were contained in a sterile plastic bag before and after sampling. All samples were transported under cold chain management and stored at $-20^{\circ} \mathrm{C} /-80^{\circ} \mathrm{C}$ before processing.

\subsection{Sample processing and metagenomic deep sequencing}

Chicken fecal samples were processed as previously described (56). Briefly, chicken fecal suspension was prepared in Phosphate-buffered saline (PBS) and treated with TURBO DNAse (Thermo Fisher, USA) 
at $37^{\circ} \mathrm{C}$ for 30 minutes, and then subjected to total nucleic acid extraction using QIAamp viral RNA mini kit (Qiagen, Germany) according to manufacturer's instruction without addition of carrier RNA. For dust samples, electrostatic cloths were incubated in 3\% beef extract buffer for 1 hour on rolling as previously published (57). After incubation, the suspension was collected and centrifugated at $4,000 \mathrm{~g}$ at $4^{\circ} \mathrm{C}$ for 4 minutes to pellet any large particles or debris. Total viruses in dust suspension were concentrated using 295 polyethylene glycol (PEG) similar to virus concentration in sewage published previously $(58,59)$. Briefly, PEG 6000 was added to each dust suspension to make up a final 10\% PEG 6000 (Sigma-Aldrich, USA) concentration, followed by $\mathrm{pH}$ adjustment to $\mathrm{pH} 4$ and overnight incubation at $4^{\circ} \mathrm{C}$ with shaking. After overnight incubation, sample was centrifuged at $13,500 \mathrm{~g}$ at $4^{\circ} \mathrm{C}$ for 90 minutes. Supernatant was removed and the remaining pellet was resuspended in $500 \mu \mathrm{L}$ of pre-warmed glycine buffer, and then subjected to 5 -minute centrifugation at $13,000 \mathrm{~g}$ at $4^{\circ} \mathrm{C}$. Supernatant was collected, and supernatants from EDC samples that were collected in the same farm at the same time point $(N=1-4)$ were pooled together for further processing. Viral-enriched dust suspension samples were then treated with TURBO DNase as previously described (56) to remove non-encapsulated DNA, followed by total nucleic acid extraction using MagMAX ${ }^{\mathrm{TM}}$ viral RNA isolation kit (Thermo Fisher, USA) according to manufacturer' instructions but without the use of carrier RNA. Reverse transcription and second strand cDNA synthesis of chicken fecal samples and dust samples was performed as previously described (56), using SuperScript III reverse transcriptase and non-ribosomal hexamers (60) (reverse transcription) and Klenow fragment 3'-5' exo- (New England BioLabs, USA) (2 ${ }^{\text {nd }}$ strand cDNA synthesis), respectively.

Standard Illumina libraries were prepared using Nextera XT DNA library kit following the manufacturer's instruction. Final libraries were sequenced on the Illumina MiSeq platform (600 cycles; paired-end). Chicken fecal samples with a multiplex range of 16-19 samples. Dust samples and negative blank controls were sequenced with a multiplex of 12 samples per run.

\subsection{Sequencing data analysis}

Raw reads were subjected to adapter removal using Trim Galore/default Illumina software, followed by quality trimming using QUASR (61) with a threshold of minimum length of $125 \mathrm{nt}$ and median Phred score $\leq 30$. Remaining reads were de novo assembled using metaSPAdes v3.12.0 (62). De novo assembled contigs were classified using UBLAST (63) against eukaryotic virus family protein databases as 
319 previously described $(22,25)$. We set a detection threshold of contig with minimum amino acid identity

320 of $70 \%$, minimum length of $300 \mathrm{nt}$ and an e-value threshold of $1 \times 10^{-10}$ when interpreting our contig

321 classification results. Contig classification results were analyzed and visualized using R packages

322 including dplyr, reshaped2 and ComplexHeatmap (64-66).

323

\subsection{Phylogenetic analysis}

Sequences with $\geq 80 \%$ of genome coverage from the Picornaviridae, Astroviridae and Caliciviridae families were used for phylogenetic analyses, comparing them with global sequences retrieved from

327 GenBank. Multiple sequence alignment was performed using MAFFT (67) and manually checked in 328 Geneious v2021.0.3 (Biomatters, New Zealand). Best-fit models of evolution for phylogenetic tree 329 reconstruction were estimated using ModelFinder module in IQ-TREE v1.6.11 (68), determined by 330 Akaike Information Criterion (AIC). Maximum-likelihood trees were constructed using RAxML-NG v1.0.1 331 (69) with 100 pseudo-replicates. Resulting trees were visualized and annotated using R package ggtree 332 (70).

\subsection{Data availability}

335 The raw reads are available in the SRA under the BioProject accession number PRJNA670873 (chicken 336 feces) and PRJNA701384 (farm dust samples) (Table S1). All sequences in phylogenetic analysis have 337 been deposited in GenBank under the accession numbers MW684778 to MW684847 (Table S2).

\section{ACKNOWLEDGMENTS}

340 We thank all the participating farms for their cooperation, Pella van der Wal and Gaby van Dijk from

341 Erasmus MC for providing sequencing service.

342 This virome study was funded by ZonMW TOP project 91217040 (K.T.T.K., M.M.T.dR., L.A.M.S., D.J.J.H. and M.P.G.K.) and a Marie Sklodowska-Curie Individual Fellowship, supported by Horizon 2020 (grant no. (M.M.T.dR., A.B.M., and I.M.W.). 


\section{AUTHOR CONTRIBUTION}

349 K.T.T.K and M.V.T.P conceived the study and performed experiments. M.M.T.dR and I.M.W. designed

350 sampling strategy. M.M.T.dR. and A.B.M. handled sample collection and collected associated metadata.

351 K.T.T.K. and M.V.T.P. analyzed data. K.T.T.K. drafted the manuscript. M.V.T.P., M.P.G.K., L.A.M.S., I.M.W.,

352 M.M.T.dR and A.B.M. edited the manuscript. M.V.T.P., M.P.G.K. and I.M.W. supervised the study.

353 M.P.G.K., D.J.J.H. and L.A.M.S. acquired the funding. 


\section{REFERENCES}

1. Jones KE, Patel NG, Levy MA, Storeygard A, Balk D, Gittleman JL, Daszak P. 2008. Global trends in emerging infectious diseases. Nature https://doi.org/10.1038/nature06536.

2. Azhar El, El-Kafrawy SA, Farraj SA, Hassan AM, Al-Saeed MS, Hashem AM, Madani TA. 2014. Evidence for camel-to-human transmission of MERS coronavirus. N Engl J Med https://doi.org/10.1056/NEJMoa1401505.

3. Hsu VP, Hossain MJ, Parashar UD, Ali MM, Ksiazek TG, Kuzmin I, Niezgoda M, Rupprecht C, Bresee J, Breiman RF. 2004. Nipah virus encephalitis reemergence, Bangladesh. Emerg Infect Dis https://doi.org/10.3201/eid1012.040701.

4. Ganter M. 2015. Zoonotic risks from small ruminants. Vet Microbiol https://doi.org/10.1016/j.vetmic.2015.07.015.

5. Chen Y, Liang W, Yang S, Wu N, Gao H, Sheng J, Yao H, Wo J, Fang Q, Cui D, Li Y, Yao X, Zhang Y, Wu H, Zheng S, Diao H, Xia S, Zhang Y, Chan KH, Tsoi HW, Teng JLL, Song W, Wang P, Lau SY, Zheng M, Chan JFW, To KKW, Chen H, Li L, Yuen KY. 2013. Human infections with the emerging avian influenza A H7N9 virus from wet market poultry: Clinical analysis and characterisation of viral genome. Lancet https://doi.org/10.1016/S0140-6736(13)60903-4.

6. Koopmans M, Wilbrink B, Conyn M, Natrop G, Van Der Nat H, Vennema H, Meijer A, Van Steenbergen J, Fouchier R, Osterhaus A, Bosman A. 2004. Transmission of H7N7 avian influenza A virus to human beings during a large outbreak in commercial poultry farms in the Netherlands. Lancet https://doi.org/10.1016/S0140-6736(04)15589-X.

7. Kalkowska DA, Boender GJ, Smit LAM, Baliatsas C, Yzermans J, Heederik DJJ, Hagenaars TJ. 2018. Associations between pneumonia and residential distance to livestock farms over a five-year period in a large population-based study. PLoS One https://doi.org/10.1371/journal.pone.0200813.

8. Smit LAM, Boender GJ, de Steenhuijsen Piters WAA, Hagenaars TJ, Huijskens EGW, Rossen JWA, Koopmans M, Nodelijk G, Sanders EAM, Yzermans J, Bogaert D, Heederik D. 2017. Increased risk of pneumonia in residents living near poultry farms: does the upper respiratory tract microbiota play a role? Pneumonia https://doi.org/10.1186/s41479-017-0027-0.

9. Kirychuk SP, Reynolds SJ, Koehncke NK, Lawson J, Willson P, Senthilselvan A, Marciniuk D, Classen 
HL, Crowe T, Just N, Schneberger D, Dosman JA. 2010. Endotoxin and dust at respirable and nonrespirable particle sizes are not consistent between cage- and floor-housed poultry operations. Ann Occup Hyg https://doi.org/10.1093/annhyg/meq047.

10. Rimac D, Macan J, Varnai VM, Vučemilo M, Matković K, Préster L, Orct T, Trošić I, Pavičić I. 2010. Exposure to poultry dust and health effects in poultry workers: Impact of mould and mite allergens. Int Arch Occup Environ Health https://doi.org/10.1007/s00420-009-0487-5.

11. Dosman JA, Fukushima Y, Senthilselvan A, Kirychuk SP, Lawson JA, Pahwa P, Cormier Y, Hurst T, Barber EM, Rhodes CS. 2006. Respiratory response to endotoxin and dust predicts evidence of inflammatory response in volunteers in a swine barn. Am J Ind Med https://doi.org/10.1002/ajim.20339.

12. Schimmer B, Dijkstra F, Vellema P, Schneeberger PM, Hackert V, ter Schegget R, Wijkmans C, van Duynhoven Y, van der Hoek W. 2009. Sustained intensive transmission of Q fever in the south of the Netherlands, 2009. Eurosurveillance 14.

13. Van Der Hoek W, Morroy G, Renders NHM, Wever PC, Hermans MHA, Leenders ACAP, Schneeberger PM. 2012. Epidemic Q fever in humans in the Netherlands. Adv Exp Med Biol https://doi.org/10.1007/978-94-007-4315-1_17.

14. Corman VM, Jores J, Meyer B, Younan M, Liljander A, Said MY, Gluecks I, Lattwein E, Bosch BJ, Drexler JF, Bornstein S, Drosten C, Müller MA. 2014. Antibodies against MERS coronavirus in dromedary camels, Kenya, 1992-2013. Emerg Infect Dis https://doi.org/10.3201/eid2008.140596.

15. Jones BA, Grace D, Kock R, Alonso S, Rushton J, Said MY, McKeever D, Mutua F, Young J, McDermott J, Pfeiffer DU. 2013. Zoonosis emergence linked to agricultural intensification and environmental change. Proc Natl Acad Sci U S A https://doi.org/10.1073/pnas.1208059110.

16. Barzon L, Lavezzo E, Militello V, Toppo S, Palù G. 2011. Applications of next-generation sequencing technologies to diagnostic virology. Int J Mol Sci.

17. Bexfield N, Kellam P. 2011. Metagenomics and the molecular identification of novel viruses. Vet J.

18. Dávila-Ramos S, Castelán-Sánchez HG, Martínez-ávila L, Sánchez-Carbente MDR, Peralta R, Hernández-Mendoza A, Dobson ADW, Gonzalez RA, Pastor N, Batista-García RA. 2019. A review on viral metagenomics in extreme environments. Front Microbiol https://doi.org/10.3389/fmicb.2019.02403. 
19. Kristensen DM, Mushegian AR, Dolja V V., Koonin E V. 2010. New dimensions of the virus world discovered through metagenomics. Trends Microbiol https://doi.org/10.1016/j.tim.2009.11.003.

20. Zheng X yan, Qiu M, Guan W jie, Li J ming, Chen S wei, Cheng M ji, Huo S ting, Chen Z, Wu Y, Jiang L na, Chen Q. 2018. Viral metagenomics of six bat species in close contact with humans in southern China. Arch Virol https://doi.org/10.1007/s00705-017-3570-3.

21. Dacheux L, Cervantes-Gonzalez M, Guigon G, Thiberge JM, Vandenbogaert M, Maufrais C, Caro V, Bourhy H. 2014. A preliminary study of viral metagenomics of french bat species in contact with humans: Identification of new mammalian viruses. PLoS One https://doi.org/10.1371/journal.pone.0087194.

22. Phan MVT, Ngo Tri T, Hong Anh P, Baker S, Kellam P, Cotten M. 2018. Identification and characterization of Coronaviridae genomes from Vietnamese bats and rats based on conserved protein domains. Virus Evol https://doi.org/10.1093/ve/vey035.

23. Chen Q, Wang L, Zheng Y, Zhang J, Guo B, Yoon KJ, Gauger PC, Harmon KM, Main RG, Li G. 2018. Metagenomic analysis of the RNA fraction of the fecal virome indicates high diversity in pigs infected by porcine endemic diarrhea virus in the United States. Virol J 15.

24. Shan T, Li L, Simmonds P, Wang C, Moeser A, Delwart E. 2011. The Fecal Virome of Pigs on a HighDensity Farm. J Virol https://doi.org/10.1128/jvi.05217-11.

25. Phan MVT, Anh PH, Cuong N Van, Munnink BBO, Hoek L Vander, My PT, Tri TN, Bryant JE, Baker S, Thwaites G, Woolhouse M, Kellam P, Rabaa MA, Cotten M. 2016. Unbiased whole-genome deep sequencing of human and porcine stool samples reveals circulation ofmultiple groups of rotaviruses and a putative zoonotic infection. Virus Evol https://doi.org/10.1093/ve/vew027.

26. Vibin J, Chamings A, Collier F, Klaassen M, Nelson TM, Alexandersen S. 2018. Metagenomics detection and characterisation of viruses in faecal samples from Australian wild birds. Sci Rep https://doi.org/10.1038/s41598-018-26851-1.

27. Vibin J, Chamings A, Klaassen M, Bhatta TR, Alexandersen S. 2020. Metagenomic characterisation of avian parvoviruses and picornaviruses from Australian wild ducks. Sci Rep https://doi.org/10.1038/s41598-020-69557-z.

28. Lima DA, Cibulski SP, Finkler F, Teixeira TF, Varela APM, Cerva C, Loiko MR, Scheffer CM, Dos Santos HF, Mayer FQ, Roehe PM. 2017. Faecal virome of healthy chickens reveals a large diversity 
of the eukaryote viral community, including novel circular ssDNA viruses. J Gen Virol https://doi.org/10.1099/jgv.0.000711.

29. Kwok KTT, Nieuwenhuijse DF, Phan MVT, Koopmans MPG. 2020. Virus metagenomics in farm animals: A systematic review. Viruses.

30. Wilkinson MD, Dumontier M, Aalbersberg ljJ, Appleton G, Axton M, Baak A, Blomberg N, Boiten JW, da Silva Santos LB, Bourne PE, Bouwman J, Brookes AJ, Clark T, Crosas M, Dillo I, Dumon O, Edmunds S, Evelo CT, Finkers R, Gonzalez-Beltran A, Gray AJG, Groth P, Goble C, Grethe JS, Heringa J, t Hoen PAC, Hooft R, Kuhn T, Kok R, Kok J, Lusher SJ, Martone ME, Mons A, Packer AL, Persson B, Rocca-Serra P, Roos M, van Schaik R, Sansone SA, Schultes E, Sengstag T, Slater T, Strawn G, Swertz MA, Thompson M, Van Der Lei J, Van Mulligen E, Velterop J, Waagmeester A, Wittenburg P, Wolstencroft K, Zhao J, Mons B. 2016. Comment: The FAIR Guiding Principles for scientific data management and stewardship. Sci Data https://doi.org/10.1038/sdata.2016.18.

31. FAO. 2021. Gateway to poultry production and products.

32. Dame-Korevaar A, Fischer EAJ, van der Goot J, Stegeman A, Mevius D. 2019. Transmission routes of ESBL/pAmpC producing bacteria in the broiler production pyramid, a literature review. Prev Vet Med.

33. Netherlandsandyou.nl. Agriculture and food: the Netherlands and Finland.

34. CBS. 2016. CBS Internationalisation Monitor 2016-II Agribusiness. The Hague.

35. Centraal Bureau voor de Statistiek. 2021. Agriculture; crops, livestock and land use by general farm type, region.

36. Finstad S, O’Bryan CA, Marcy JA, Crandall PG, Ricke SC. 2012. Salmonella and broiler processing in the United States: Relationship to foodborne salmonellosis. Food Res Int https://doi.org/10.1016/j.foodres.2011.03.057.

37. Silva J, Leite D, Fernandes M, Mena C, Gibbs PA, Teixeira P. 2011. Campylobacter spp. As a foodborne pathogen: A review. Front Microbiol.

38. Sims LD, Domenech J, Benigno C, Kahn S, Kamata A, Lubroth J, Martin V, Roeder P. 2005. Origin and evolution of highly pathogenic H5N1 avian influenza in Asia. Vet Rec https://doi.org/10.1136/vr.157.6.159.

39. De Rooij MMT, Borlée F, Smit LAM, De Bruin A, Janse I, Heederik DJJ, Wouters IM. 2016. 
Detection of Coxiella Burnetii in ambient air after a large $Q$ fever outbreak. PLoS One https://doi.org/10.1371/journal.pone.0151281.

40. Zhao Y, Richardson B, Takle E, Chai L, Schmitt D, Xin H. 2019. Airborne transmission may have played a role in the spread of 2015 highly pathogenic avian influenza outbreaks in the United States. Sci Rep https://doi.org/10.1038/s41598-019-47788-z.

41. Viegas S, Faísca VM, Dias H, Clérigo A, Carolino E, Viegas C. 2013. Occupational exposure to poultry dust and effects on the respiratory system in workers. J Toxicol Environ Heal - Part A Curr Issues https://doi.org/10.1080/15287394.2013.757199.

42. Danuser B, Weber C, Künzli N, Schindler C, Nowak D. 2001. Respiratory symptoms in Swiss farmers: An epidemiological study of risk factors. Am J Ind Med https://doi.org/10.1002/ajim.1032.

43. Cambra-López M, Torres AG, Aarnink AJA, Ogink NWM. 2011. Source analysis of fine and coarse particulate matter from livestock houses. Atmos Environ https://doi.org/10.1016/j.atmosenv.2010.10.018.

44. Munk P, Knudsen BE, Lukjacenko O, Duarte ASR, Van Gompel L, Luiken REC, Smit LAM, Schmitt H, Garcia AD, Hansen RB, Petersen TN, Bossers A, Ruppé E, Graveland H, van Essen A, Gonzalez-Zorn B, Moyano G, Sanders P, Chauvin C, David J, Battisti A, Caprioli A, Dewulf J, Blaha T, Wadepohl K, Brandt M, Wasyl D, Skarzyńska M, Zajac M, Daskalov H, Saatkamp HW, Stärk KDC, Lund O, Hald T, Pamp SJ, Vigre H, Heederik D, Wagenaar JA, Mevius D, Aarestrup FM. 2018. Abundance and diversity of the faecal resistome in slaughter pigs and broilers in nine European countries. Nat Microbiol https://doi.org/10.1038/s41564-018-0192-9.

45. Gardy JL, Loman NJ. 2018. Towards a genomics-informed, real-time, global pathogen surveillance system. Nat Rev Genet.

46. Luiken REC, Van Gompel L, Bossers A, Munk P, Joosten P, Hansen RB, Knudsen BE, García-Cobos S, Dewulf J, Aarestrup FM, Wagenaar JA, Smit LAM, Mevius DJ, Heederik DJJ, Schmitt H. 2020. Farm dust resistomes and bacterial microbiomes in European poultry and pig farms. Environ Int https://doi.org/10.1016/j.envint.2020.105971.

47. Scoizec A, Niqueux E, Thomas R, Daniel P, Schmitz A, Le Bouquin S. 2018. Airborne detection of H5N8 highly pathogenic avian influenza virus genome in poultry farms, France. Front Vet Sci 
https://doi.org/10.3389/fvets.2018.00015.

48. Lau SKP, Woo PCY, Yip CCY, Li KSM, Fan RYY, Bai R, Huang Y, Chan KH, Yuen KY. 2014. Chickens host diverse picornaviruses originated from potential interspecies transmission with recombination. J Gen Virol https://doi.org/10.1099/vir.0.066597-0.

49. Boros Á, Pankovics P, Adonyi Á, Fenyvesi H, Day JM, Phan TG, Delwart E, Reuter G. 2016. A diarrheic chicken simultaneously co-infected with multiple picornaviruses: Complete genome analysis of avian picornaviruses representing up to six genera. Virology https://doi.org/10.1016/j.virol.2015.12.002.

50. Lefkowitz EJ, Dempsey DM, Hendrickson RC, Orton RJ, Siddell SG, Smith DB. 2018. Virus taxonomy: The database of the International Committee on Taxonomy of Viruses (ICTV). Nucleic Acids Res https://doi.org/10.1093/nar/gkx932.

51. Donato C, Vijaykrishna D. 2017. The broad host range and genetic diversity of mammalian and avian astroviruses. Viruses.

52. Wolf S, Reetz J, Hoffmann K, Gründel A, Schwarz BA, Hänel I, Otto PH. 2012. Discovery and genetic characterization of novel caliciviruses in German and Dutch poultry. Arch Virol https://doi.org/10.1007/s00705-012-1326-7.

53. Jonges M, Van Leuken J, Wouters I, Koch G, Meijer A, Koopmans M. 2015. Wind-mediated spread of low-pathogenic avian influenza virus into the environment during outabreaks at commercial poultry farms. PLoS One https://doi.org/10.1371/journal.pone.0125401.

54. Noss I, Doekes G, Sander I, Heederik DJJ, Thorne PS, Wouters IM. 2010. Passive airborne dust sampling with the electrostatic dustfall collector: Optimization of storage and extraction procedures for endotoxin and glucan measurement. Ann Occup Hyg https://doi.org/10.1093/annhyg/meq026.

55. Liebers V, Van Kampen V, Bünger J, Düser M, Stubel H, Brüning T, Raulf-Heimsoth M. 2012. Assessment of airborne exposure to endotoxin and pyrogenic active dust using Electrostatic Dustfall Collectors (EDCs). J Toxicol Environ Heal - Part A Curr Issues https://doi.org/10.1080/15287394.2012.674919.

56. Kwok KTT, de Rooij MMT, Messink AB, Wouters IM, Koopmans MPG, Phan MVT. 2020. Genome Sequences of Seven Megrivirus Strains from Chickens in The Netherlands. Microbiol Resour 
Announc https://doi.org/10.1128/mra.01207-20.

57. Prussin AJ, Torres PJ, Shimashita J, Head SR, Bibby KJ, Kelley ST, Marr LC. 2019. Seasonal dynamics of DNA and RNA viral bioaerosol communities in a daycare center. Microbiome https://doi.org/10.1186/s40168-019-0672-z.

58. Strubbia S, Schaeffer J, Oude Munnink BB, Besnard A, Phan MVT, Nieuwenhuijse DF, de Graaf M, Schapendonk CME, Wacrenier C, Cotten M, Koopmans MPG, Le Guyader FS. 2019. Metavirome sequencing to evaluate norovirus diversity in sewage and related bioaccumulated oysters. Front Microbiol https://doi.org/10.3389/fmicb.2019.02394.

59. Nieuwenhuijse DF, Oude Munnink BB, Phan MVT, Hendriksen RS, Bego A, Rees C, Neilson EH, Coventry K, Collignon P, Allerberger F, Rahube TO, Oliveira G, Ivanov I, Sopheak T, Vuthy Y, Yost CK, Tabo D adjim, Cuadros-Orellana S, Ke C, Zheng H, Baisheng L, Jiao X, Donado-Godoy P, Coulibaly KJ, Hrenovic J, Jergović M, Karpíšková R, Elsborg B, Legesse M, Eguale T, Heikinheimo A, Villacis JE, Sanneh B, Malania L, Nitsche A, Brinkmann A, Saba CKS, Kocsis B, Solymosi N, Thorsteinsdottir TR, Hatha AM, Alebouyeh M, Morris D, O'Connor L, Cormican M, Moran-Gilad J, Battisti A, Alba P, Shakenova Z, Kiiyukia C, Ng'eno E, Raka L, Bērziňš A, Avsejenko J, Bartkevics V, Penny C, Rajandas H, Parimannan S, Haber MV, Pal P, Schmitt H, van Passel M, van de Schans MGM, Zuidema T, Jeunen GJ, Gemmell N, Fashae K, Wester AL, Holmstad R, Hasan R, Shakoor S, Rojas MLZ, Wasyl D, Bosevska G, Kochubovski M, Radu C, Gassama† A, Radosavljevic V, Tay MYF, Zuniga-Montanez R, Wuertz S, Gavačová D, Trkov M, Keddy K, Esterhuyse K, Cerdà-Cuéllar M, Pathirage S, Larsson DGJ, Norrgren L, Örn S, Van der Heijden T, Kumburu HH, de RodaHusman AM, Njanpop-Lafourcade BM, Bidjada P, Nikiema-Pessinaba SC, Levent B, Meschke JS, Beck NK, Van Dang C, Tran DMN, Do Phuc N, Kwenda G, Munk P, Venkatakrishnan S, Aarestrup FM, Cotten M, Koopmans MPG. 2020. Setting a baseline for global urban virome surveillance in sewage. Sci Rep https://doi.org/10.1038/s41598-020-69869-0.

60. Endoh D, Mizutani T, Kirisawa R, Maki Y, Saito H, Kon Y, Morikawa S, Hayashi M. 2005. Speciesindependent detection of RNA virus by representational difference analysis using non-ribosomal hexanucleotides for reverse transcription. Nucleic Acids Res 33:e65.

61. Watson SJ, Welkers MRA, Depledge DP, Coulter E, Breuer JM, de Jong MD, Kellam P. 2013. Viral population analysis and minority-variant detection using short read next-generation sequencing. 
Philos Trans R Soc B Biol Sci https://doi.org/10.1098/rstb.2012.0205.

62. Nurk S, Meleshko D, Korobeynikov A, Pevzner PA. 2017. MetaSPAdes: A new versatile metagenomic assembler. Genome Res https://doi.org/10.1101/gr.213959.116.

63. Edgar RC. 2010. Search and clustering orders of magnitude faster than BLAST. Bioinformatics https://doi.org/10.1093/bioinformatics/btq461.

64. Wickham H, François R, Henry L, Müller K. 2019. dplyr: A Grammar of Data Manipulation.

65. Wickham H. 2007. Reshaping data with the reshape package. J Stat Softw https://doi.org/10.18637/jss.v021.i12.

66. Gu Z, Eils R, Schlesner M. 2016. Complex heatmaps reveal patterns and correlations in multidimensional genomic data. Bioinformatics https://doi.org/10.1093/bioinformatics/btw313.

67. Katoh K, Misawa K, Kuma KI, Miyata T. 2002. MAFFT: A novel method for rapid multiple sequence alignment based on fast Fourier transform. Nucleic Acids Res https://doi.org/10.1093/nar/gkf436.

68. Nguyen LT, Schmidt HA, Von Haeseler A, Minh BQ. 2015. IQ-TREE: A fast and effective stochastic algorithm for estimating maximum-likelihood phylogenies. Mol Biol Evol https://doi.org/10.1093/molbev/msu300.

69. Kozlov AM, Darriba D, Flouri T, Morel B, Stamatakis A. 2019. RAxML-NG: A fast, scalable and userfriendly tool for maximum likelihood phylogenetic inference. Bioinformatics https://doi.org/10.1093/bioinformatics/btz305.

70. Yu G, Smith DK, Zhu H, Guan Y, Lam TTY. 2017. ggtree: an r package for visualization and annotation of phylogenetic trees with their covariates and other associated data. Methods Ecol Evol https://doi.org/10.1111/2041-210X.12628. 


\section{Figure legends}

Figure 1. An overview of virus contigs detected in chicken feces and chicken farm dust samples. Each column represents one sample. Associated metadata is shown at the top panel. The color intensity of the heatmap (bottom panel) is determined by number of contigs with minimum length of $300 \mathrm{nt} / \mathrm{bp}$, at least $70 \%$ identity and an e-value threshold of $1 \times 10^{-10}$ when comparing with closest reference in our database. Sample order is assorted by farm ID, sampling time point. Time point is an arbitrary number. Samples were collected at the same time and place when both Farm ID and Time point match.

Figure 2. An overview of picornavirus contigs detected in chicken feces and chicken farm dust samples. Each column represents one sample. Associated metadata is shown at the top panel. The color intensity of the heatmap (bottom panel) is determined by number of contigs with minimum length of $300 \mathrm{nt}$, at least $70 \%$ identity and an e-value threshold of $1 \times 10^{-10}$ when comparing with closest reference in our database. Sample order is assorted by farm ID, sampling time point. Time point is an arbitrary number. Samples were collected at the same time and place when both Farm ID and Time point match.

Figure 3. Maximum-likelihood phylogenetic tree of 76 (sequences from this study: 46; reference sequences: 30 ) picornavirus partial polyprotein amino acid sequences (3786 sites) reconstructed using a best-fit evolutionary model LG+FC+R10. For clarity, only bootstrap supports $>=70$ are shown as a navyblue node point. Tip labels of our samples are colour-coded by corresponding farm ID. Reference sequences are in grey. Tree was mid-point rooted for clarity.

Figure 4. Maximum-likelihood phylogenetic tree of 30 sicinivirus partial polyprotein nucleotide sequences (sequences from this study: 15; reference sequences: 15; 8672 sites) reconstructed using a best-fit evolutionary model GTR+F+R10. For clarity, only bootstrap supports $>=70$ are shown as a navyblue node point. Tip labels of our samples are colour-coded by corresponding farm ID. Reference sequences are in grey and tree was mid-point rooted for clarity. 
Figure 5. A. Maximum-likelihood phylogenetic tree of 33 astrovirus partial RdRp amino acid sequences (sequences from this study: 16; reference sequences: 17; 548 sites) reconstructed using a best-fit evolutionary model LG+FC+I+G4m. B. Maximum-likelihood phylogenetic tree of 33 astrovirus partial capsid amino acid sequences (sequences from this study: 16; reference sequences: 17; 908 sites) reconstructed using a best-fit evolutionary model $\mathrm{LG}+\mathrm{FC}+\mathrm{I}+\mathrm{G} 4 \mathrm{~m}$. For clarity, only bootstrap supports $>=$ 70 are shown as a navy-blue node point. Tip labels of our samples are colour-coded by corresponding farm ID. Reference sequences are in grey and tree was mid-point rooted for clarity.

Figure 6. Maximum-likelihood phylogenetic tree of 30 calicivirus partial polyprotein amino acid sequences (sequences from this study: 14; reference sequences: 16; 2794 sites) reconstructed using a best-fit evolutionary model LG+FC+R10. For clarity, only bootstrap supports $>=70$ are shown as a navyblue node point. Tip labels of our samples are colour-coded by corresponding farm ID. Reference sequences are in grey and tree was mid-point rooted for clarity. 
Table 1. Prevalence of different eukaryotic virus families in chicken feces and farm dust samples

\begin{tabular}{|c|c|c|c|}
\hline \multicolumn{2}{|c|}{ Sample types } & Chicken feces (N=51) & Farm dust (N=13) \\
\hline \multirow{3}{*}{} & Astroviridae & $42(82 \%)$ & $11(85 \%)$ \\
\cline { 2 - 4 } & Caliciviridae & $40(78 \%)$ & $9(69 \%)$ \\
\cline { 2 - 4 }$\frac{\bar{\varepsilon}}{\frac{\pi}{\pi}}$ & Coronaviridae & $19(37 \%)$ & $3(23 \%)$ \\
\cline { 2 - 4 } & Parvoviridae & $51(100 \%)$ & $13(100 \%)$ \\
\cline { 2 - 4 } & Picobirnaviridae & $8(16 \%)$ & $2(15 \%)$ \\
\cline { 2 - 4 } & Picornaviridae & $51(100 \%)$ & $11(85 \%)$ \\
\cline { 2 - 4 } & Reoviridae & $7(14 \%)$ & $3(23 \%)$ \\
\hline
\end{tabular}

Table 2. Prevalence of picornavirus genera in chicken feces and farm dust samples

\begin{tabular}{|c|c|c|c|}
\hline \multicolumn{2}{|c|}{ Sample types } & Chicken feces ( $N=51)$ & Farm dust $(\mathrm{N}=13)$ \\
\hline \multirow{6}{*}{ 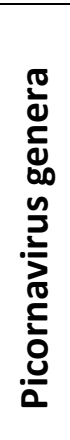 } & Anativirus & $36(70 \%)$ & $8(61 \%)$ \\
\hline & Avisivirus & $3(5 \%)$ & $0(0 \%)$ \\
\hline & Gallivirus & $16(31 \%)$ & $4(30 \%)$ \\
\hline & Megrivirus & $22(43 \%)$ & $6(46 \%)$ \\
\hline & Orivirus & $8(15 \%)$ & $0(0 \%)$ \\
\hline & Sicinivirus & $51(100 \%)$ & $9(69 \%)$ \\
\hline
\end{tabular}


Table 3. Detailed sampling strategy

\begin{tabular}{|c|c|c|c|c|c|}
\hline Farm \# & $\begin{array}{l}\text { Sampling } \\
\text { moment } \\
\text { identifier }\end{array}$ & $\begin{array}{l}\text { Time } \\
\text { point }\end{array}$ & $\begin{array}{l}\text { No. of pooled } \\
\text { fecal } \\
\text { sample(s) } \\
\text { collected }\end{array}$ & $\begin{array}{l}\text { No. of pooled EDC } \\
\text { sample(s) collected } \\
\text { (no. of individual EDC } \\
\text { sample[s] collected) }\end{array}$ & $\begin{array}{l}\text { Week } \\
\text { production } \\
\text { cycle }\end{array}$ \\
\hline \multirow{5}{*}{ F_01 } & F_01_1 & 1 & 4 & $1(4)$ & 3 \\
\hline & F_01_2 & 2 & 4 & $1(4)$ & 4 \\
\hline & F_01_3 & 3 & 4 & $1(4)$ & 5 \\
\hline & F_01_4 & 4 & 4 & $1(1)$ & 4 \\
\hline & F_01_5 & 5 & 4 & $0(0)$ & 5 \\
\hline \multirow{5}{*}{ F_02 } & F_02_1 & 1 & 4 & $1(2)$ & 4 \\
\hline & F_02_2 & 2 & 4 & $1(4)$ & 5 \\
\hline & F_02_3 & 3 & 4 & $1(4)$ & 2 \\
\hline & F_02_4 & 4 & 4 & 1 (4) & 4 \\
\hline & F_02_5 & 5 & 4 & $1(4)$ & 5 \\
\hline \multirow{4}{*}{ F_03 } & F_03_1 & 1 & 4 & $1(3)$ & 4 \\
\hline & F_03_2 & 2 & 4 & $1(4)$ & 5 \\
\hline & F_03_3 & 3 & 4 & $1(4)$ & 4 \\
\hline & F_03_4 & 4 & 4 & $1(4)$ & 5 \\
\hline
\end{tabular}




\section{Supplementary materials legends.}

Figure S1. An overview of virus family prevalence in chicken feces and farm dust samples. Associated metadata is shown at the top panel. The color intensity of the heatmap (bottom panel) is determined by number of contigs with minimum length of $300 \mathrm{nt}$, at least $70 \%$ identity and an e-value threshold of $1 \times 10^{-10}$ when comparing with closest reference in our database. Sample order is assorted by farm ID, sampling time point. Time point is an arbitrary number. Samples were collected at the same time and place when both Farm ID and Time point match.

Figure S2. An overview of picornavirus genera prevalence in chicken feces and farm dust samples. Associated metadata is shown at the top panel. The color intensity of the heatmap (bottom panel) is determined by number of contigs with minimum length of $300 \mathrm{nt}$, at least $70 \%$ identity and an e-value threshold of $1 \times 10^{-10}$ when comparing with closest reference in our database. Sample order is assorted by farm ID, sampling time point. Time point is an arbitrary number. Samples were collected at the same time and place when both Farm ID and Time point match.

Table S1. A list of corresponding BioProject, BioSample and SRA accession numbers for all samples.

Table S2. A list of corresponding GenBank accession numbers for sequences used in phylogenetic analyses. 


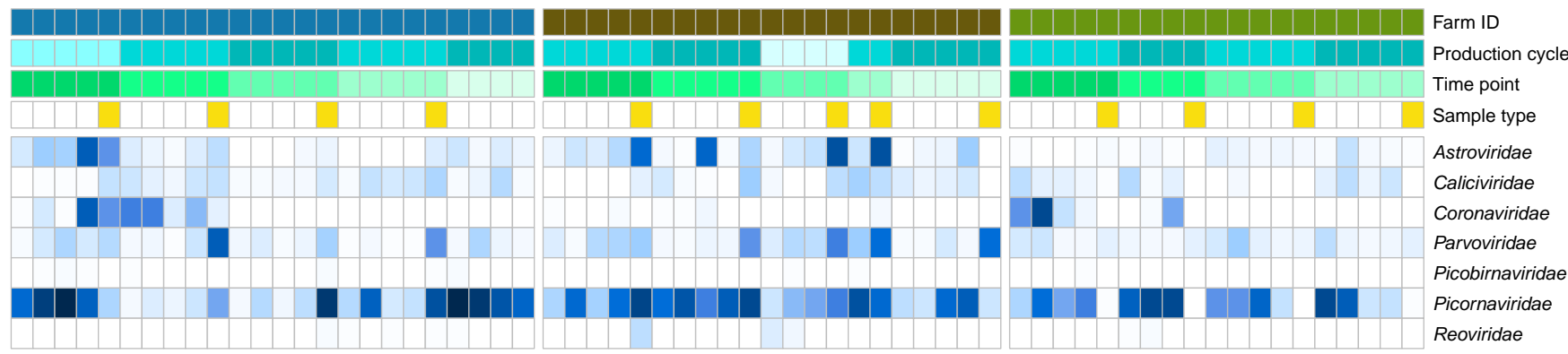

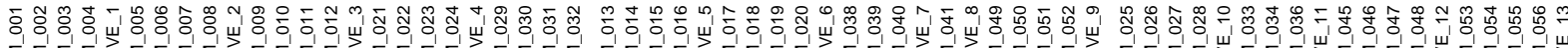

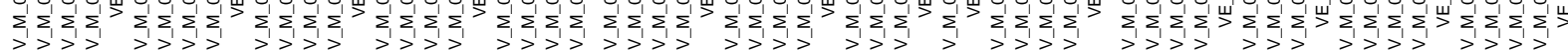

\begin{tabular}{|c|c|} 
Farm ID & Production cycl \\
\hline F_01 & Week 2 \\
\hline F_02 & Week 3 \\
\hline F_03 & Week 4 \\
& Week 5
\end{tabular}

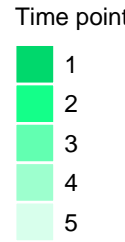

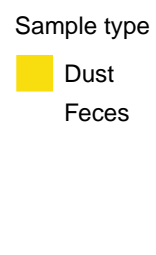

No. of contigs

(id $\%>=70$, length $>=300$ )

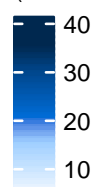




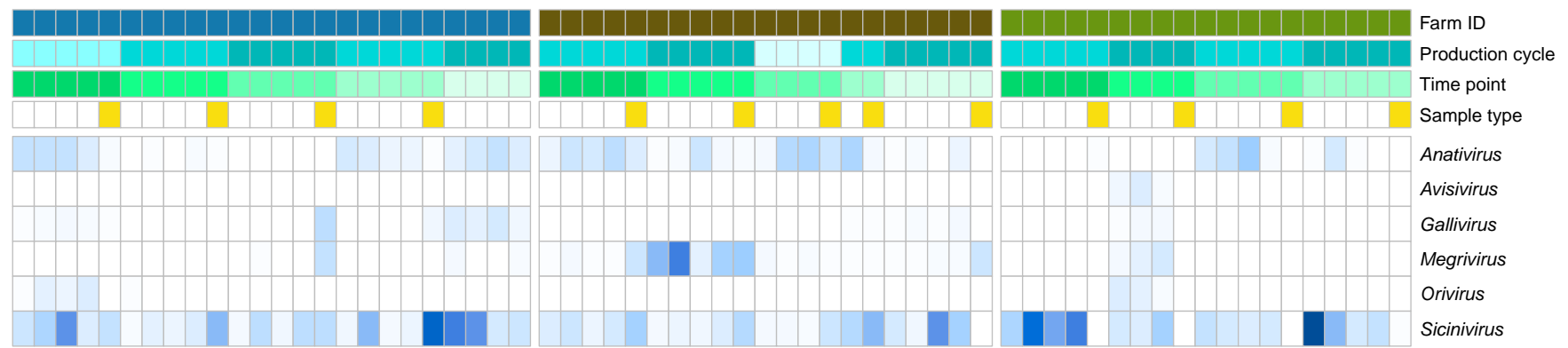

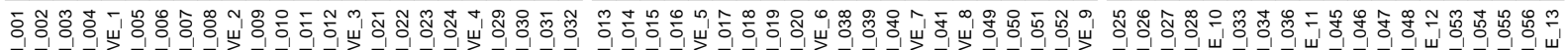

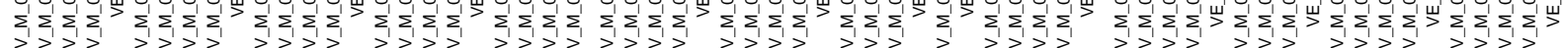

\begin{tabular}{|c|c|c|} 
Farm ID & Production cycle & Time point \\
\hline F_01 & Week 2 & 1 \\
\hline F_02 & Week 3 & 2 \\
\hline F_03 & Week 4 & 3 \\
& Week 5 & 4 \\
& & 5
\end{tabular}

No. of contigs

(id\% $>=70$, length $>=300$ )

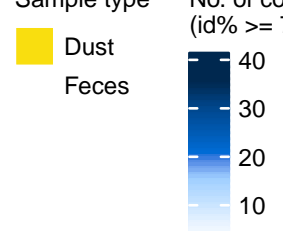


- Chicken_KT880665_PfCHK1SiV HUN 2013

i Chicken_V_M_017_picorna_4

Chicken V M 019 picorna 4

— Chicken_V_M_056_picorna_2

Chicken_V_M_050_picorna_3

bioRxiv preprint doi: https://doi.org/10.1101/2021.03.09.434704; this version posted March 10, 2021. The copyright hotder picorna 68 this preprint (which was not certified by peer review) is the author/funder, who has granted bioRxiv a license to display the preprint in perpeteiityndt is made

\section{(which was not certified by peer review) is the author/funder, who has granted bioRxiv a license to display the greprint in perpeteityntut is made}

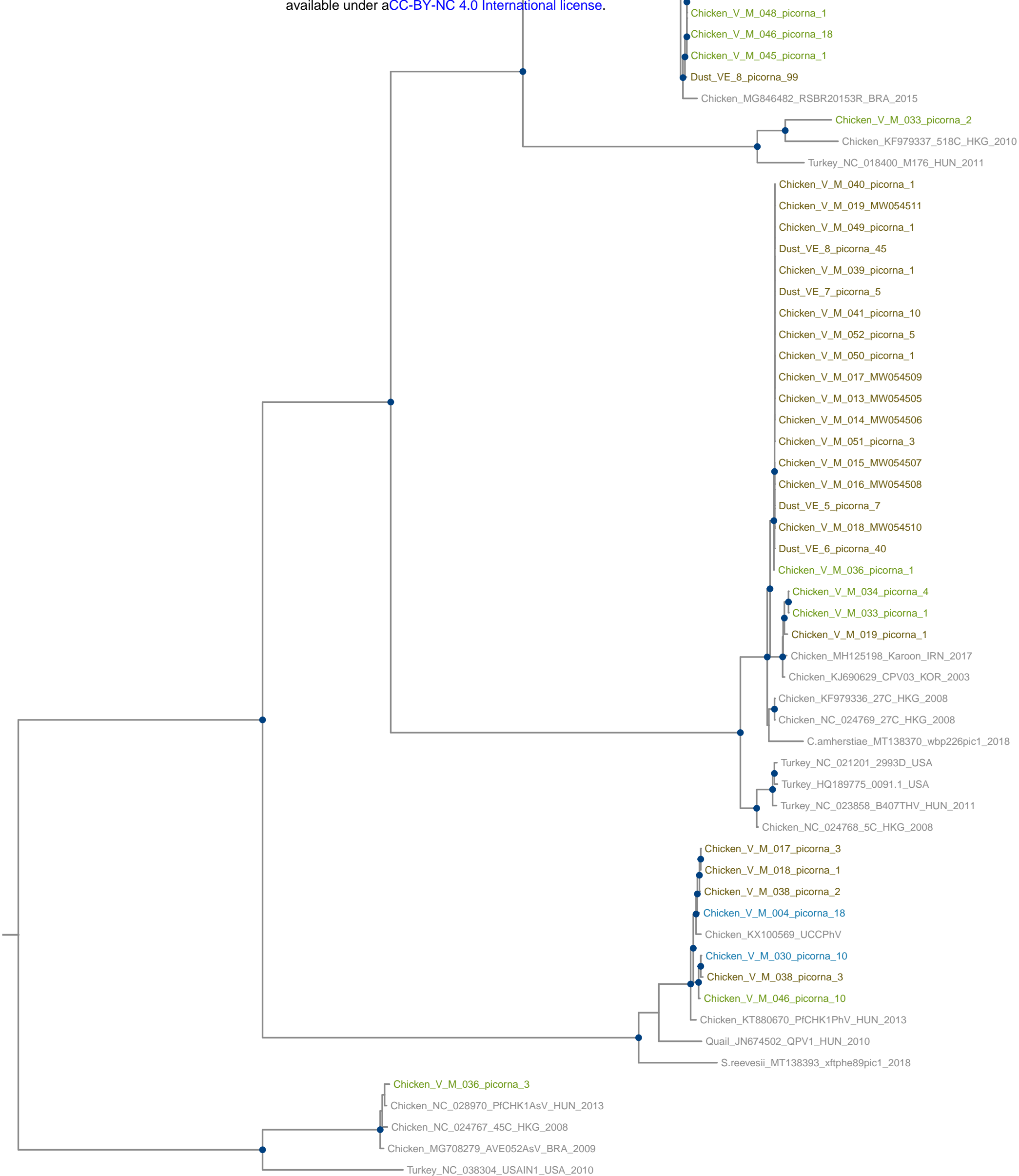




\section{Farm ID}

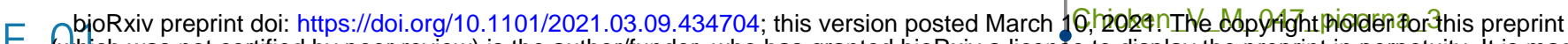
_ (which was not certified by peer review) is the author/funder, who has granted bioRxiv a license to display the preprint in perpetuity. It is made F_02

F_03 available under aCC-BY-NC 4.0 International license eircken_V_M_046_picorna_18

Chicken_V_M_045_picorna_1

Dust_VE_8_picorna_99

Chicken MG846482 RSBR20153R BRA 2015 Chicken MN873047 GA1478 USA_2003

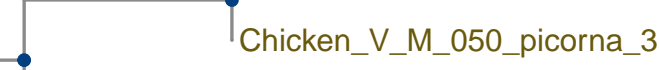

Chicken_V_M_056_picorna_2

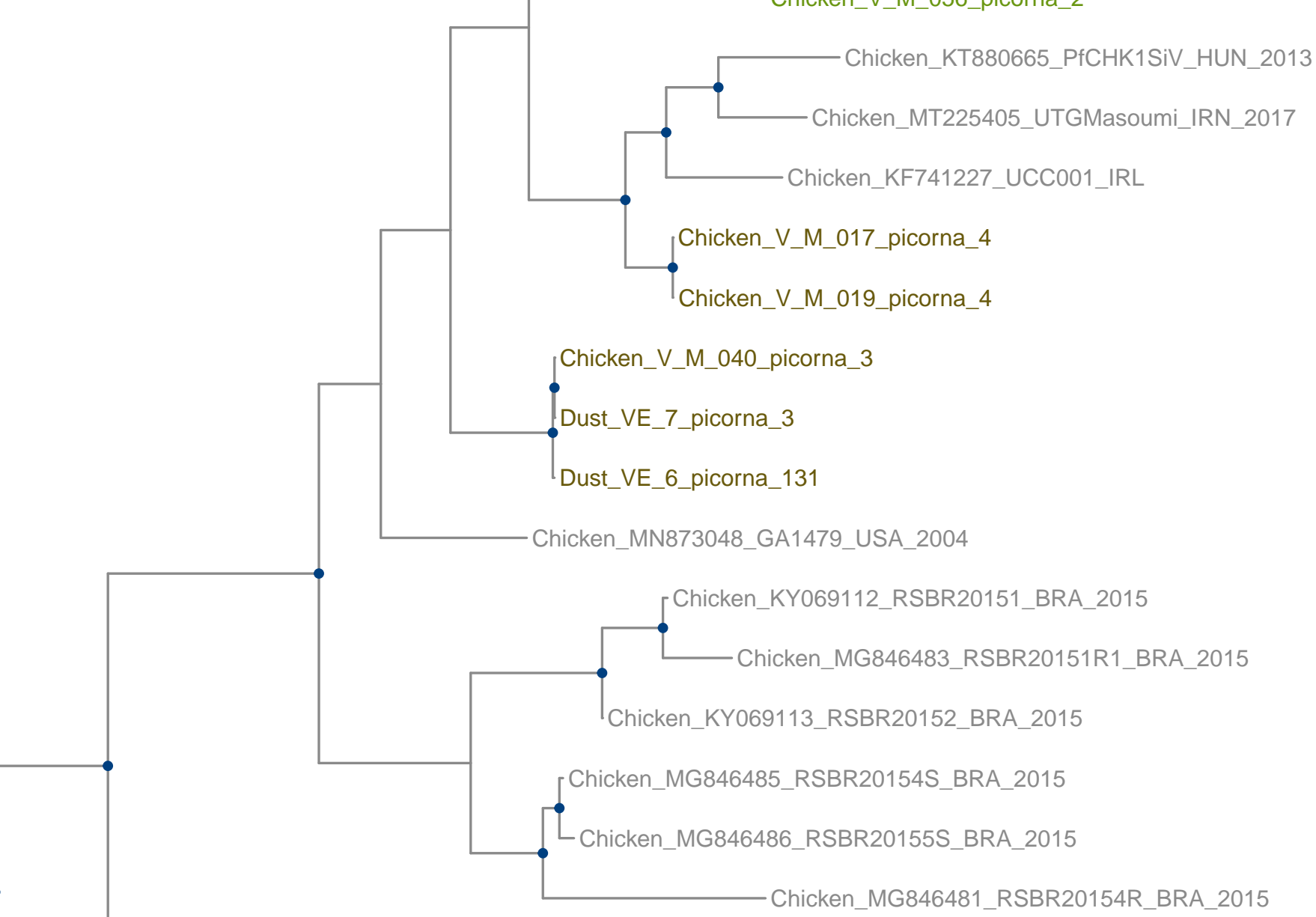

Chicken NC 024765 55C HKG 2008

Chicken_KF979332_100C_HKG 2009

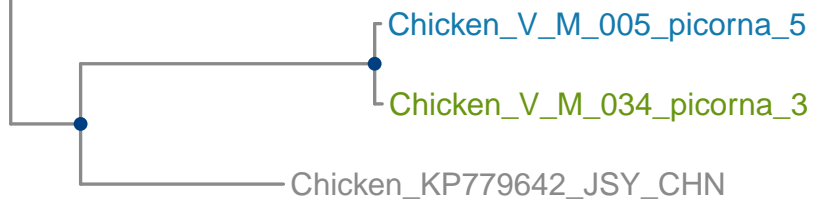



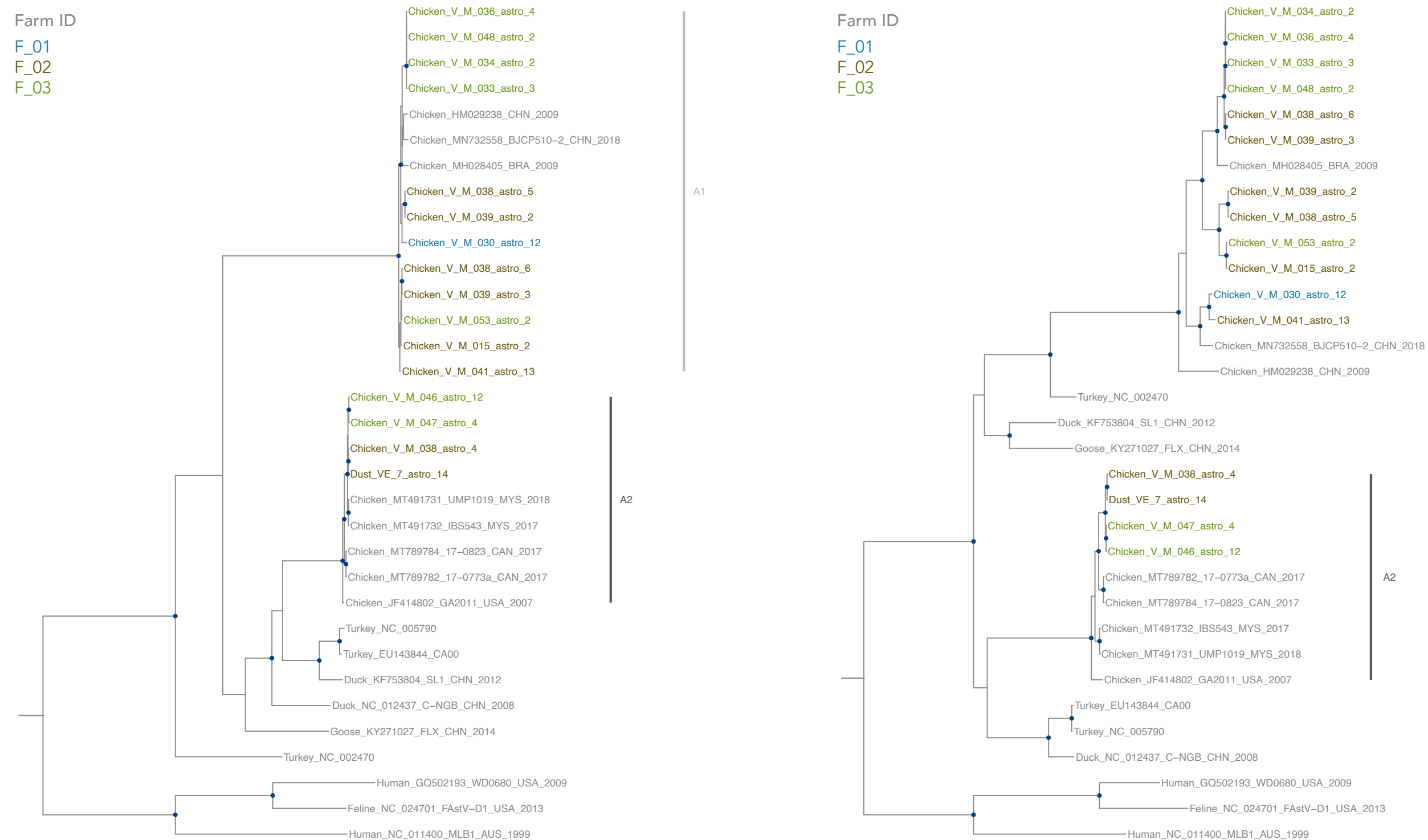
F bioRxiv preprint doi: https://doi.org/10.1101/2021.03.09.434704; this version posted March 10, 2021t. The cop\&rigat hołder for this preprint -_ which was not certified by peer review) is the author/funder, who has granted bioRxiv a license to display the preprint in perpetuity. It is made
available under aCC-BY-NC 4.0 International license. F_02

F_03

Chicken_V_M_041_calici_11

-Chicken_V_M_050_calici_2

-Chicken_V_M_051_calici_5

Chicken_V_M_019_calici_3

Chicken_V_M_030_calici_8

Chicken_V_M_056_calici_1

Chicken_V_M_053_calici_1

Chicken_V_M_054_calici_1

Chicken_V_M_036_calici_2

Chicken_JQ347523_F10026n_DEU_2010

Chicken_JQ347527_F10034n_DEU_2010

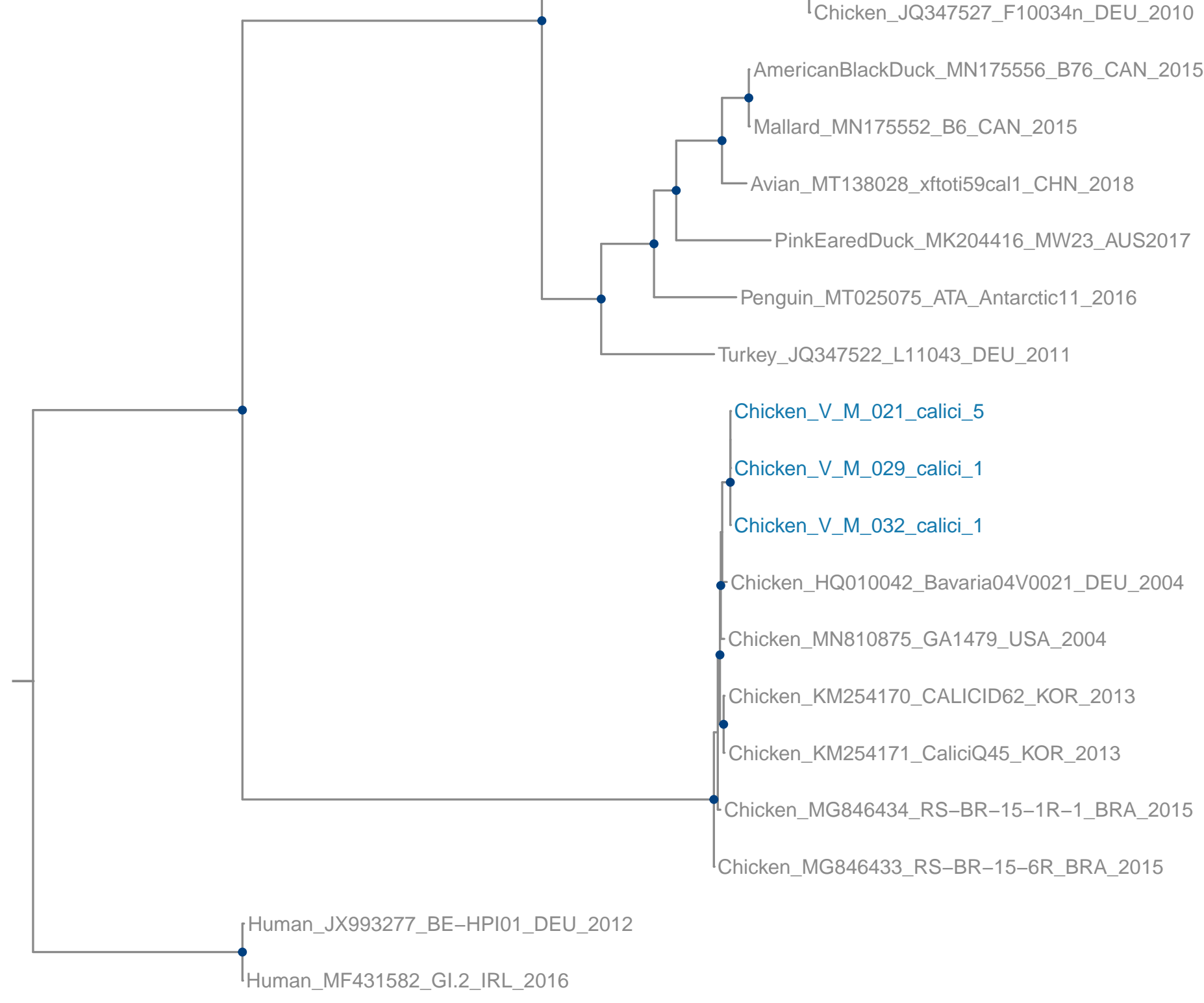

